\title{
Morphological Characterization of Self-Assembled Pd Nanowires by Electroless Deposition
}

\author{
Zhongliang Shi ${ }^{*}$ Jerzy A Szpunar ${ }^{*}$, and Shanqiang $\mathrm{Wu}^{* *}$ \\ *Department of Mining, Metals and Materials Engineering, McGill University, M. H. Wong \\ Building, 3610 University, Montreal, H3A 2B2 Canada \\ ${ }^{* *}$ AH2T Inc., 225 President Kennedy Avenue, PK6230, Montreal, H2X 3 Y 8 Canada
}

Hydrogen is deemed to be the fuel of the future as it is clean and in abundance. With the widespread use of hydrogen as a fuel, two types of sensors should be developed: one for detection of such impurities in the fuel, which could harm the fuel cells, and the other type should address safety concern and provide reliable information on hydrogen leaks [1]. Metallic nanowires exhibit a broad range of low-dimensional effects and have a potential application in nanoelectronic, nanophotonic and sensor devices. A small hydrogen detector which is low-cost, reliable and reusable and needs minimal power to operate, has been proposed and developed at the University of California at Irvine [2][3][4]. Research on the use of the fiber optic technology for sensing the presence of hydrogen is also being conducted by the National Aeronautics and Space Administration, DCH Technology and the National Renewable Energy Laboratory. The future hydrogen sensors will likely differ for the automotive market, the stationary market and the miniature fuel cell market. Electrochemical deposition is one of the most widely used methods to process continuous nanowires using some nanopore templates. Especially, electroless deposition can be developed a simple and inexpensive tool to be used to deposit uniform and dense Pd membranes on any arbitrary shape and complex substrates. But so far, there is no any report of this process for Pd nanowires preparation on stainless steel substrate. In this paper, we explore a simple, controllable method to fabricate Pd nanowires and to investigate their microstructural characteristics.

Electroless deposition is a three-step process: (1) pretreatment of the substrate; (2) sensitization and activation of the substrate surface; (3) electroless deposition. In this project a porous 316L stainless steel plate was purchased from Mott Metallurgical Corporation. Its average pore size is $0.2 \mu \mathrm{m}$. The detailed experimental description for electroless deposition of Pd was described elsewhere [5]. Microstructure characteristics of the sample was observed and analyzed by PHILIPS XL30 FEG SEM with EDS (GENESIS 2000 X-ray Microanalysis System).

The electroless deposition of $\mathrm{Pd}$ can be described as a combination of cathodic deposition of palladium and anodic reaction at the immersion potential.

Anodic reaction: $\mathrm{N}_{2} \mathrm{H}_{4}+4 \mathrm{OH}^{-1} \rightarrow \mathrm{N}_{2}+4 \mathrm{H}_{2} \mathrm{O}+4 \mathrm{e}^{-}$

Cathodic reaction: $2 \mathrm{Pd}\left[\mathrm{NH}_{3}\right]_{4}{ }^{2+}+4 \mathrm{e}^{-} \rightarrow 2 \mathrm{Pd}^{\mathrm{o}}+8 \mathrm{NH}_{3}$

Autocatalytic reaction: $2 \mathrm{Pd}\left[\mathrm{NH}_{3}\right]_{4}{ }^{2+}+\mathrm{N}_{2} \mathrm{H}_{4}+4 \mathrm{OH}^{-1} \rightarrow 2 \mathrm{Pd}^{\mathrm{o}}+\mathrm{N}_{2}+4 \mathrm{H}_{2} \mathrm{O}+8 \mathrm{NH}_{3}$

Figure 1 shows the SEM micrographs of the deposited $\mathrm{Pd}$ nanowires on the rough stainless steel surface. As it can be seen, most of the deposited Pd nanowires are continuous. These images also show that the Pd nanowires are composed of nanosize Pd particles which connect together bead-bybead. Figure $1(b, d)$ represents images of the net-like Pd nanowires, which can not be built from electrochemical deposition due to the electric field between electrodes. 
For conclusion, we have successfully deposited Pd nanowires on the rough stainless steel surface. The diameter of these wires is approximately $100 \mathrm{~nm}$ and most of them are continuous, and special net-like nanowires patterns are formed.

\section{References}

[1] E.C. Walter, F. Favier, and R.M. Penner. Analytical Chemistry, 74 (2002) 1546

[2] F. Favier, E. C. Walter, M. P. Zach, T. Benter, R. M. Penner, Science. 293 (2001) 2227

[3] E.C. Walter, R.M. Penner, H. Liu, et al., Surface and Interface Analysis, 34 (2002) 409

[4] E.C. Walter, B.J. Murray, F. Favier, et al., J. Phys. Chem. B, 106, (2002) 11407

[5] J. Shu, B.P.A. Grandjean, S. Kaliaguine, Thin Solid Film, 252 (1994) 26
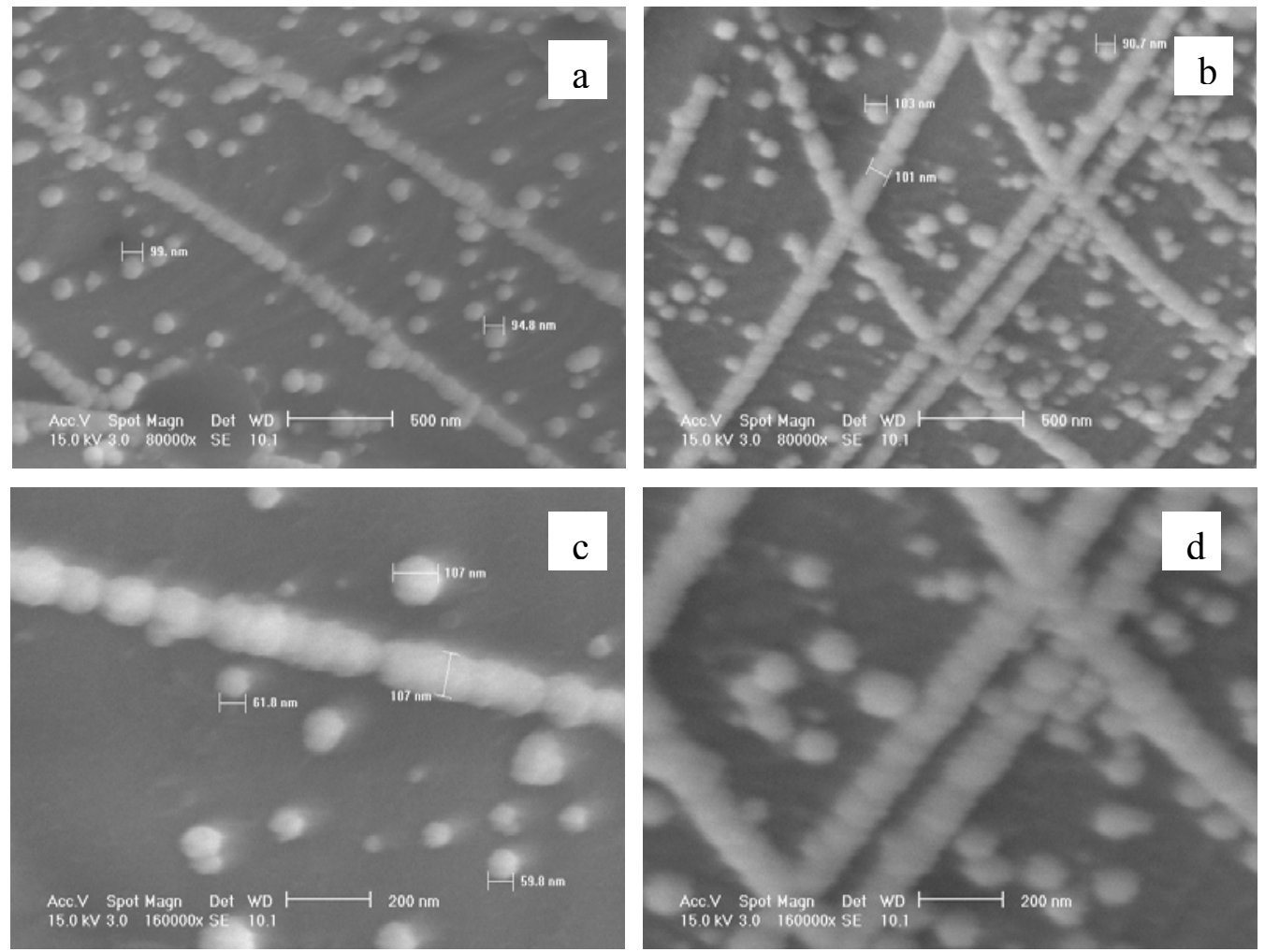

Fig. 1. Scanning electron micrographs (a-d) of Pd nanowires by electroless deposition in 2 minutes
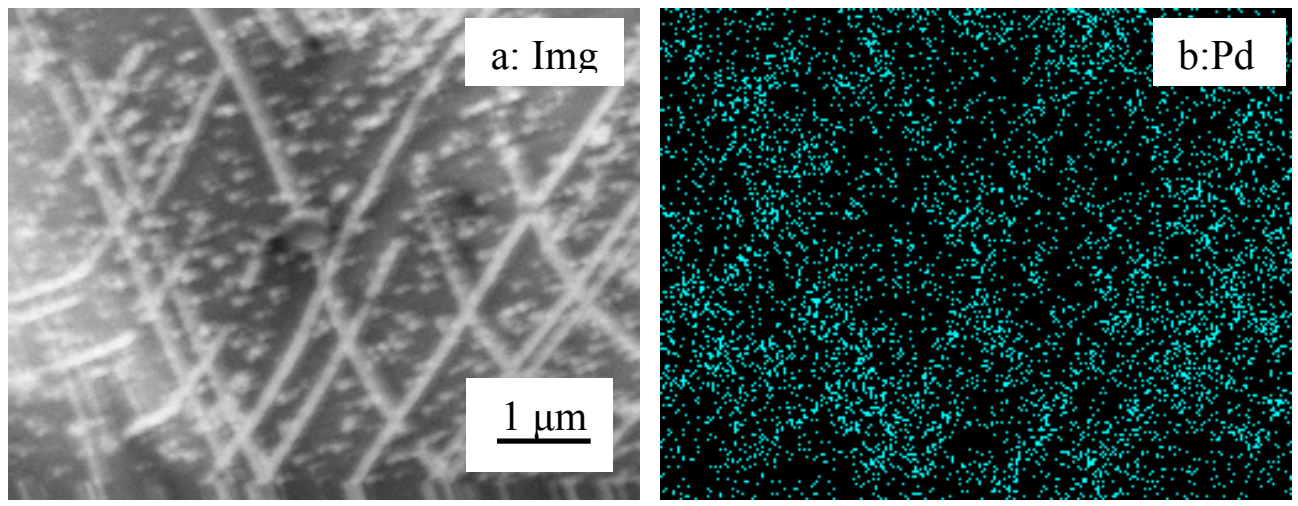

Fig. 2. SEM image (a) and its palladium mapping (b) via EDAX 